\title{
Nevrokognitivne osnove numeričnega procesiranja
}

\author{
Klinični oddelek za otroško, mladostniško in razvojno ne \\ Tina Bregant*
}

Povzetek: V prispevku predstavimo nekaj novejših spoznanj s področja numerične kognicije in nevrokognitivnih osnov numeričnega procesiranja. Osnovo numerične kognicije predstavlja prepoznava in primerjava količin. Ker je ta sistem prepoznaven tako pri dojenčkih kot nekaterih živalskih vrstah, ga podrobneje predstavimo. Osnovni sistem ali matematično intuicijo lahko nadgradimo s kompleksnejšim, aritmetičnim procesiranjem, ki ga predstavimo v luči novejših nevroznanstvenih spoznanj. Spoznanja o numeričnem procesiranju lahko pomembno prispevajo $\mathrm{k}$ razumevanju matematičnih kompetenc $\mathrm{v}$ različnih obdobjih otrokovega razvoja ter tako prispevajo h kakovosti poučevanja matematike ter usvajanju matematičnih znanj in veščin.

Ključne besede: numerično procesiranje, štetje, matematične sposobnosti, možgani, razvoj otroka

\section{Brain mechanisms underlying numerical processing}

Tina Bregant

Department of Child, Adolescent and Developmental Neurology, University Medical Centre Ljubljana, Slovenia

\begin{abstract}
In the paper we present some of the recent findings in the field of numerical processing and brain mechanisms underlying these processes. Quantity estimation and comparison represent the basics of numerical processing. We present this system more in details as this core quantity system is well recognized in infants as well as in some animal species. Core quantity system which is also called mathematical intuition, can be extended by a more complex, arithmetic processing, which is also presented within the article. Understanding the brain mechanisms which underlay numerical processing can help us understand and develop mathematical competence, which represents one of the key cognitive abilities that is acquired through formal schooling.
\end{abstract}

Key words: numerical processing, counting, mathematical ability, brain, child development

\footnotetext{
${ }^{*}$ Naslov/Address: Tina Bregant, dr. med., Klinični oddelek za otroško, mladostniško in razvojno nevrologijo, Pediatrična klinika, Univerzitetni klinični center Ljubljana, Bohoričeva 20,1000 Ljubljana, e-mail: tina.bregant.drmed@gmail.com

Članek je licenciran pod pogoji Creative Commons Attribution 4.0 International licence. (CC-BY licenca).

The article is licensed under a Creative Commons Attribution 4.0 International License (CC-BY license).
} 
S številkami se srečujemo vsak dan. Že ko ste vzeli v roke revijo, ste prebrali, kdaj je izšla in kako je številčno označena. Če ste se odločili za branje točno določenega prispevka, ste morali prepoznati številko strani, na kateri se nahaja, in revijo prelistati. Že s temi uvodnimi besedami ste lahko zaznali dileme, ki jih imamo pri preučevanju numeričnega procesiranja. Številke so namreč abstraktni simboli, ki lahko pomenijo različne stvari: količino kot npr. trije članki ali pa zaporedje: npr. tretji (lahko je to zadnji) članek. Številke lahko zapišemo simbolično na več načinov: tri ali 3 ali III ali pa nesimbolično, npr. tri pike in prav vsi zapisi pomenijo enako količino.

Preiskave s funkcijskim magnetno-resonančnim slikanjem (slikanje s fMR) so omogočile prepoznavo možganskih struktur, ki omogočajo numerično, pa tudi matematično procesiranje. Osnovno numerično procesiranje povezujemo $\mathrm{z}$ aktivacijo horizontalnega segmenta intraparietalnega sulkusa (angl. horizontal segment of the intraparietal sulcus - hIPS) (Dehaene, Piazza, Pinel in Cohen, 2003), ki ga edinega tudi povezujemo zgolj s številčnimi informacijami, neodvisno od konteksta (Thioux, Pesenti, De Volder in Seron, 2002), medtem ko je za kompleksnejše matematične procese ali procesiranje zahtevnejših konceptov, kot so negativne vrednosti, nujno usklajeno delovanje več področij (Blair, Rosenberg-Lee, Tsang, Schwartz in Menon, 2012; Grabner, Reishofer, Koschutnig in Ebner, 2011).

$\mathrm{V}$ prispevku predstavimo nevrokognitivne osnove numeričnega procesiranja, pri čemer opišemo dva različna koncepta procesiranja. Intuitivni koncept, ki je vrojen in ga poznajo tudi živali, omogoča prepoznavo količine in je ključnega pomena pri razvoju matematičnih kompetenc. Matematično procesiranje, ki vključuje računsko prakso, uporabo jezika in uporabo kognitivno zahtevnejših konceptov, kot so iracionalna in negativna števila, je bolj kompleksno. Predstavimo ga preko novejših nevroznanstvenih študij, ki ponudijo prenekateri odgovor, vendar pa tudi odpirajo mnoga vprašanja.

\section{Prepoznava in primerjanje količin - osnova numerične kognicije}

Ocenjevanje številčnosti neke skupine, primerjanje dveh števil po velikosti ter osnovno seštevanje (dodajanje) in odštevanje (odvzemanje) so najverjetneje biološko določene sposobnosti, ki jih opažamo tudi pri nekaterih živalskih vrstah. Presoja, npr. kje bo veverica našla več orehov ali v kateri čredi je možnost ulova največja, je živalim prirojena, saj je pomembna za obstoj vrste. Tudi ljudje imamo vrojen občutek za števila.

Dojenčki že kmalu po rojstvu, večinoma pri treh mesecih, postanejo pozorni na številčnost niza predmetov. Pri šestih mesecih vizualno ločijo skupini z osmimi in šestnajstimi elementi, pri enajstih mesecih pa že izražajo poznavanje ordinalnosti (Dehaene, Molko, Cohen in Wilson, 2004). Ta občutek za količino imenujemo tudi matematična intuicija, saj so te presoje hitre, avtomatične in brez introspekcije (Dehaene, 2009). Intuicija ne zajema kompleksnih matematičnih operacij in kognitivno zahtevnih konceptov kot so ulomki, koreni, negativna in realna števila. Slednje razvijemo in razumemo šele z izobraževanjem oziroma se jih priučimo. Pri matematični intuiciji gre torej zgolj za osnovno razumevanje števil, ki je prisotno celotno življenjsko obdobje in ga poznajo tudi nekatere živalske vrste.

Intraparietalni sulkus (IPS), predvsem njegov horizontalni del (hIPS), je aktiven pri vseh številskih nalogah in pri vseh predstavitvah količine (Dehaene idr., 2003). Predel hIPS se aktivira avtomatično, amodalno in ne glede na vrsto številčnega zapisa (Thioux idr., 2002). Zato mislimo, da predel hIPS predstavlja specializirano področje za številsko procesiranje in je povezano $\mathrm{z}$ določanjem količine, ki se začne že $\mathrm{v}$ zgodnjem otroštvu. Okvare tega področja lahko povzročijo motnje pri aritmetičnem procesiranju, ki jih zelo težko odpravimo. Med motnje, ki jih povezujemo z okvaro tega področja, torej predvsem $\mathrm{z}$ okvarami v področju levega parietalno-temporalnega režnja, sodi tudi razvojna oblika diskalkulije. Razvojna oblika diskalkulije je specifična učna težava, ki se pojavlja s prevalenco $3-6 \%$ v populaciji in jo povezujemo s poškodbo predela ob intraparietalnem sulkusu (Dehaene idr., 2004). Otroci z razvojno obliko diskalkulije kažejo ob sicer normalnem gibalnem, govornem, kognitivnem in socialnem razvoju, nezmožnost usvajanja aritmetičnih sposobnosti, kar se kaže kot težave pri razbiranju informacij iz tabel, slabše razumevanje algoritmov aritmetičnih operacij, lahko nastopijo tudi težave pri razumevanju koncepta števil ali pa ti otroci ne zmorejo povezati govorjene in pisane besede s številom.

Danes velja, da je za abstraktno, numerično predstavljeno količino nujna aktivacija intraparietalnega sulkusa (Ansari, 2007). Obstajajo pa razlike med desnim in levim IPS. Tako se je izkazalo, da je levi IPS aktiven ne glede na modalnost in vrsto zapisa, medtem ko je desni IPS bolj aktiven pri številčnem zapisu, torej zapisu z arabskimi števkami (Ansari, 2007). Ugotovili so tudi, da se asimetrija aktivnosti v IPS izraža tako pri avtomatičnem kot pri hotenem aritmetičnem procesiranju (Cohen Kadosh, Bien in Sack, 2012).

\section{Numerična kognicija pri živalih}

Živali zelo verjetno ne štejejo v lingvističnem pomenu štetja. Najverjetneje živali ne preštevajo oziroma štejejo ena, dve, tri ..., lahko pa sklepamo iz različnih študij (Cantlon in Brannon, 2007; Pepperberg 2002), da imajo določene živalske vrste vrojeno sposobnost razločevanja in določanja količine. Najbolj verjetno je sposobnost določanja količine predstavljala evolucijsko prednost predvsem pri teritorialnih živali. Prav ta sposobnost jim namreč omogoča določiti teritorij, kjer je več hrane za celotno skupino.

Rosa Rugani je s sodelavci objavila zanimivo študijo o piščančkih (Rugani, Fontanari, Simoni, Regolin in Vallortigara, 2009), kjer se je izkazalo, da komaj izvaljeni piščančki že razlikujejo manjše količine. V študiji so 
namreč piščančkom predstavili mamo kot določeno število predmetov (npr. tri stebrički). Ko so umaknili enega ali več stebričkov, pri čemer so bili pozorni na prostorsko predstavo, so se piščančki zmedli in zelo dolgo iskali manjkajočo "mamo" oz. njen del. Podobno so količino znale oceniti druge ptice: taščice (Garland, Low in Burns, 2012) in papige (Pepperberg, 2002).

Koncepte količine prepoznavajo tudi sesalci. Med najbolj preučevanimi so delfini in opice. Delfini pri lovu sledijo posebni tehniki, ki jo lahko interpretiramo preko matematičnih pravil. Znanstveniki sklepajo glede na njihovo vedenje pri lovu, da morajo delfini seštevati, odštevati in celo množiti oziroma so sposobni primerjati količine na zelo kompleksne načine (Leighton, Richards in White, 2004). Makaki znajo oceniti manjše količine ne glede na modalnost - torej ali je dražljaj viden ali slišen (Jordana, MacLean in Brannon, 2008). Zmorejo tudi razločevati sete po količini, ne glede na barvo, velikost ali obliko (Cantlon in Brannon, 2007). Glede na rezultate raziskave, kjer so med poskusom nekaj predmetov umaknili, znajo makaki tudi odštevati, saj so praviloma izbrali količinsko pravilni ostanek (Jordana idr., 2008).

Raziskave pri živalih potrjujejo tezo, da za osnovno določanje količine obstajajo živčne strukture, ki so se skozi evolucijo specializirale le za določanje količine in so neodvisne od ostalih predelov, npr. za govor. Te strukture so prisotne in aktivne tako pri nekaterih živalskih vrstah kot že pri dojenčkih in nam omogočajo določitev in primerjanje količine ter osnovne matematične aktivnosti in tako predstavljajo temelje za nadaljnje, kompleksnejše matematične procese.

\section{Aritmetično procesiranje v možganih}

Aritmetično procesiranje je bolj kompleksen proces kot zgolj določanje in primerjanje količine. S fMR lahko opazujemo usklajeno, kompleksno aktivacijo več možganskih predelov. Pri računanju se aktivirajo temenski oziroma parietalni, prefrontalni in cingularni režnji (Chochon, Cohen, Moortele in Dehaene, 1999; Dehaene idr., 2004). Intraparietalni sulkus (IPS), še posebej njegov horizontalni del (hIPS), ki je ključen za osnovno določanje količine, je aktiven pri vseh številskih nalogah in pri vseh predstavitvah količine, ne glede na zapis količine in modalnost.

Precentralni reženj in spodnji del prefrontalnega režnja se aktivirata pri mentalnem računanju. Parietalna skorja (angl. parietal cortex - PC) in prefrontalna skorja (angl. prefrontal cortex - PFC) sta funkcionalno povezana, zato bi lahko sklepali, da se numerična informacija iz PC prenese $\mathrm{v}$ PFC, kjer se okrepi in zadrži do primernega odgovora oziroma vedenja. Področji PC in PFC sprejemata abstraktne informacije o količini, hkrati pa sta aktivni pri izvršitvi dejanja, saj prav tam potekajo ključni procesi kategorizacije, odločanja, delovnega spomina in ciljnega vedenja (Nieder in Dehaene, 2009).

Procesiranje numerične informacije povezujemo $\mathrm{z}$ aktivacijo temenskih režnjev. Ko so preiskovancem predstavili številke $\mathrm{v}$ obliki pik ali pa kot arabske številke, se je aktiviralo temensko področje. Če se je količina ali način predstavitve $\mathrm{v}$ predstavljenem vzorcu spremenil, se je aktivacija predela ponovno ojačala, kar lahko razumemo kot procesiranje numerične informacije. Bolj ko se je količina razlikovala, bolj močna je bila sprememba (Piazza, Pinel, Le Bihan in Dehaene, 2007). V študiji so med numeričnim procesiranjem zaznali tudi razlike $\mathrm{v}$ obeh hemisferah. Leva hemisfera je bila bolj aktivna med abstraktnimi numeričnimi reprezentacijami, medtem ko je bila desna aktivnejša med primerjanjem in poimenovanjem številk. Razlike med hemisferama so bile najbolj očitne pri primerjavi števil in pri računanju. Rezultati sovpadajo s prejšnjimi raziskavami(Chochonidr., 1999), ki so pokazale, da je med primerjanjem dveh števil intraparietalna in prefrontalna dejavnost močnejša v desni hemisferi, pri množenju v levi hemisferi, pri odštevanju pa je aktivnost prisotna obojestransko. Zanimivo, da bolniki $\mathrm{z}$ afazijo in akalkulijo $\mathrm{z}$ močno poškodbo leve hemisfere kljub nezmožnosti poimenovanja, seštevanja, odštevanja in množenja vseeno pravilno določijo, katero od dveh števil je večje. Tako sklepamo, da za primerjavo števil zadostuje le aktivna desna hemisfera, čeprav sta pri primerjanju števil običajno aktivni obe hemisferi. Pri poimenovanju in računanju pa se praviloma aktivira le leva hemisfera (Chochon idr., 1999).

Obsežna meta-analiza o branju, numeričnem procesiranju in kognitivnem nadzoru, ki vsi vplivajo na učno uspešnost otrok, je pokazala, da se pri otrocih, za razliko od odraslih, med numeričnim procesiranjem primarno aktivira čelni reženj. Šele zzorenjem možganskih struktur in pridobivanjem dodatnih matematičnih izkušenj, se aktivnost premika v prid temenskega režnja. Zanimivoje, da je pri branju aktivacija struktur pri odraslih in otrocih zelo podobna; podobno velja pri preizkusih izvršilnih funkcij, kjer pa zaradi nezrelosti struktur pri otrocih zahtevajo aktivacijo sprednjega dela skorje inzule in pri najstnikih dodatno okrepitev desnega sprednjega dela inzule (Houdé, Rossi, Lubin in Joliot, 2010).

Prvi predlagani model numeričnega procesiranja sta predstavila v študijah Dehaene in Cohen (Dehaene idr., 2003) in velja še danes z nekaterimi dopolnili. Prve študije so pokazale na tri predele, ki so ključni za numerično procesiranje:

1) Bilateralni predeli ob intraparietalnem sulkusu (IPS) med procesiranjem numerične količine, torej katera številka je večja.

2) Temensko področje, predvsem levo, ki ga imenujemo angularni girus (AG), med računanjem.

3) Bilateralni zgornji predeli temenske skorje, ki jih povezujemo s pozornostjo in vidno-prostorskimi zaznavami, ki so potrebne med numeričnim ali matematičnim procesiranjem.

Na sliki 1 so shematsko predstavljeni predeli, ki se aktivirajo pri numeričnem procesiranju. S svetlejšo sivo so predstavljeni predeli, ki sta jih že prepoznala v študijah 


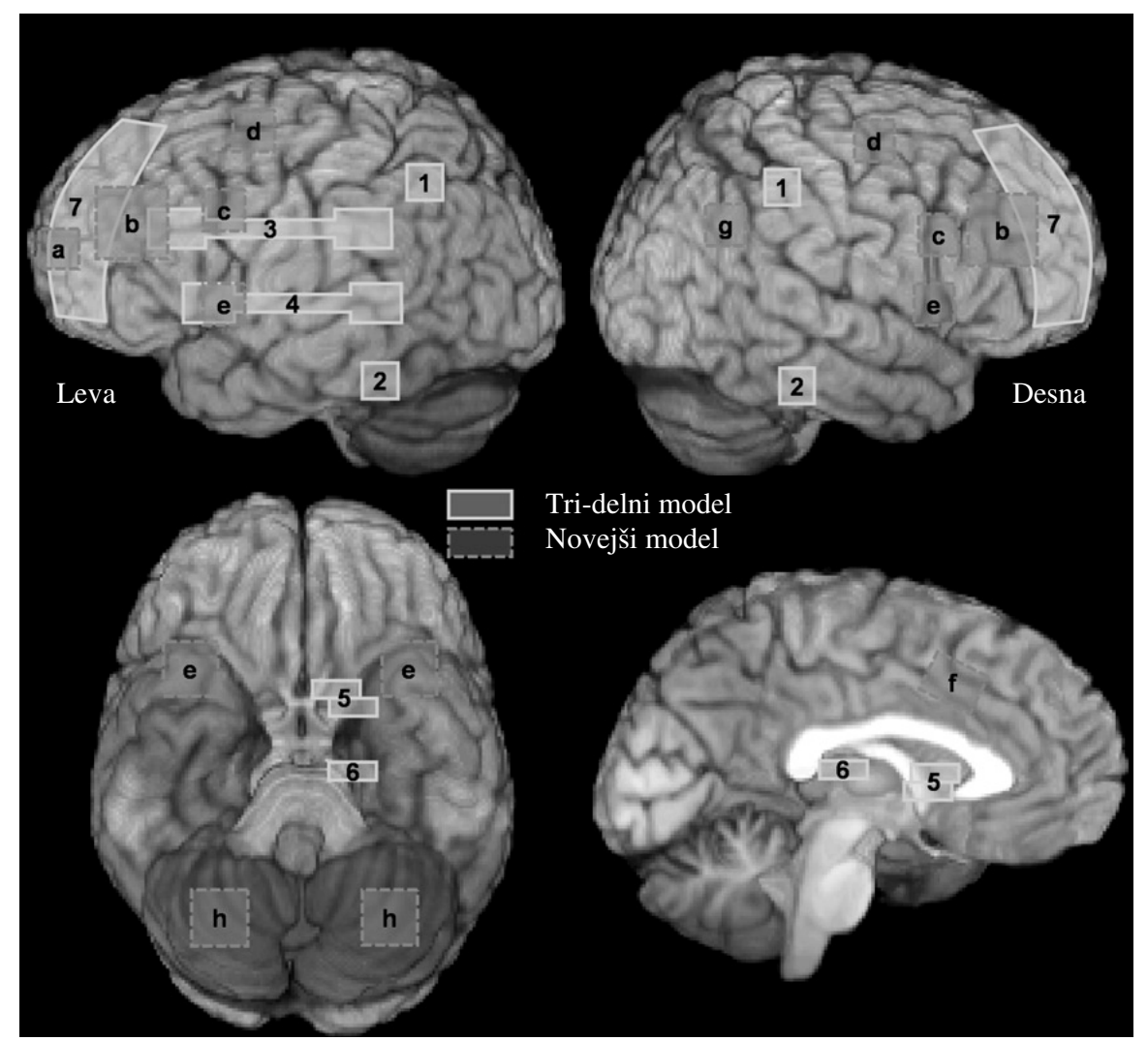

Slika 1. Shematska predstavitev predelov, ki se aktivirajo pri aritmetičnem procesiranju. S svetlejšo sivo so predstavljeni predeli, ki sta jih prepoznala v študijah Dehaene in Cohen (Dehaene idr., 2003), s temnejšo sivo pa predeli, ki jih je navajalo več študij in katerih pomembnost je pokazala šele meta analiza raziskav (Arsalidou in Taylor, 2011). (Prirejeno po Arsalidou, M. in Taylor, M.J. (2011). Is $2+2=4$ ? Meta analyses of brain areas needed for numbers and calculations. Neuroimage, 54, 2382-2393.)

Dehaene in Cohen (Dehaene idr., 2003) in so bili povzeti $\mathrm{v}$ njunem tri-delnem modelu. Danes je tri-delni model dodatno razčlenjen in ga delimo na:

1) Bilateralni predeli ob intraparietalnem sulkusu (IPS) med procesiranjem numerične količine, torej katera številka je večja.

2) Senčnični predel - vidna predstava količine

3) Artikulacijska zanka

4) Govorni predel

5) Bazalni gangliji - aritmetična dejstva

6) Talamus - aritmetična dejstva

7) Prefrontalna skorja - izbira strategije in načrtovanje računske operacije/reševanje matematičnega problema.

Na sliki 1 so s temnejšo sivo označeni predeli, ki jih je navajalo več študij in ki so bili identificirani šele $s$ pomočjo meta-analize (Arsalidou in Taylor, 2011):

a) Medialni in superiorni girusi čelnega režnja načrtovanje, stopenjsko reševanje problema

b) Srednji girusi čelnega režnja - zahtevnejši, večstopenjski problemi

c) Spodnji del čelnega režnja - nadzor nad preprostimi problemi d) Precentralni girus - očesni gibi

e) Insula - samodejno izvajanje procesov

f) Cingulatni girus - implementacija miselnih procesov

g) Desni girus angularis - priklic vidno - prostorskih zaznav

h) Mali možgani - usmerjeno, vidno-gibalno usklajevanje.

$\mathrm{Ob}$ numeričnem procesiranju sodelujejo tudi subkortikalne strukture, katerih vloga pa še ni čisto razjasnjena. Glede na študije lahko sklenemo, da je aritmetično procesiranje zelo kompleksna kognitivna funkcija možganov, ki zahteva usklajeno delovanje več različnih predelov možganov.

\section{Matematične kompetence}

Numerična kognicija je sposobnost procesiranja numerične oziroma številčne informacije. Glavno vlogo pri tem igra že predstavljen predel skorje temenskega režnja. Sposobnost reševanja osnovnih aritmetičnih problemov je dodatno odvisna od kakovosti povezav med levim in desnim temenskim predelom. Za reševanje kompleksnejših matematičnih problemov, torej za aritmetično procesiranje pa je potrebno usklajeno 
delovanje več možganskih področij. Usklajeno delovanje zahteva fleksibilne povezave več predelov, števila je potrebno povezati $\mathrm{z}$ besedami in s količinsko predstavo, izbrati je potrebno najbolj ustrezno metodo za reševanje določenega problema, algoritmom je potrebno dati pomen in razumevanje.

Računanje $\mathrm{z}$ večmestnimi števili je kompleksen in dolgotrajen proces, pri katerem se aktivira več možganskih predelov, med njimi tudi prefrontalni reženj, ki ima kontrolno vlogo, kadar naša dejanja ne potekajo avtomatično (Stanescu-Cosson idr., 2000; De Smedt, Holloway in Ansari, 2011). Tudi angularni girus (AG) je dejaven pri nekaterih aritmetičnih nalogah, npr. množenju, vendar bolj v lingvistični povezavi (Dehaene idr., 2004). Aritmetične operacije so namreč povezane $\mathrm{z}$ uporabo jezika. Pri reševanju aritmetičnih problemov z arabskimi števili se števila najprej pretvorijo v besedo, $\mathrm{s}$ katero dostopimo do verbalnega spomina o aritmetičnih dejstvih. Grabner je s sodelavci (2011), objavil študijo, v kateri so raziskovali aktivnost možganskih področij pri odraslih osebah z boljšimi ali slabšimi matematičnimi kompetencami. Ugotovili so, da se aktivnost v IPS med proučevanima skupinama ni razlikovala, pojavile pa so se razlike $v$ aktivnosti angularnega girusa. Pri bolj kompetentnih posameznikih je bila aktivnost levega AG večja. Celo več, bila je linearno odvisna od dosežkov na matematičnih testih. Predpostavlja se, da se večje matematične kompetence izražajo v večji aktivnosti levega AG, a le pri reševanju novih, neznanih nalog. Lahko bi sklepali, da je levi AG povezan z matematično kognicijo in ne le s priklicem aritmetičnih dejstev iz spomina.

Poleg razumevanja aritmetičnih nalog je za uspešnost pri matematičnih nalogah zelo pomembno prepoznavanje numerične informacije iz diagramov, tabel in enačb. Gre torej za sposobnost razbiranja numeričnih informacij iz različnih formatov. Podatki iz raziskav nakazujejo, da so matematično "sposobnejši”" posamezniki boljši ne toliko v priklicu aritmetičnih znanj, pač pa v delovanju višjih, kognitivnih procesov, zlasti pri procesiranju matematičnih simbolov. Pri dobrih matematikih se ti procesi zelo aktivno odvijajo v levem angularnem girusu, ki je pri njih bolj dejaven kot pri slabih matematikih.

Med aritmetičnimi nalogami je komunikacija med obema hemisferama močnejša, kot če gre samo za količinsko oceno. V študijah so najhitreje računali tisti preiskovanci, ki so imeli najmočnejše povezave med obema hemisferama. Sklepamo lahko, da visoka koherenca živčne aktivnosti v obeh temenskih predelih pomeni optimalnejšo sposobnost računanja. To bi lahko tudi pomenilo, da neučinkovita komunikacija med obema predeloma prispeva k slabšim matematičnim sposobnostim (Piazza, 2010).

\section{Zaključek}

Sposobnost procesiranja osnovne numerične informacije nam je vrojena. Ocenjevanje velikosti in primerjanje količine poznajo že majhni otroci in nekatere živalske vrste in ga povezujemo $\mathrm{z}$ aktivnostjo predela ob intraparietalnem sulkusu - IPS. Aktivnost, ki jo nekateri znanstveniki poimenujejo kar matematična intuicija, predstavlja osnovo za vse kompleksnejše numerične procese in razumevanje kompleksnejših matematičnih pojmov.

Učenje števil, prilagojeno potrebam in zmožnostim posameznika, in z začetkom že $\mathrm{v}$ predšolskem obdobju, vpliva na izboljšanje matematičnih sposobnosti. Dobro poznavanje števil in količinske predstave, za katere je nujno normalno delovanje nekaterih možganskih predelov, predvsem predelov ob intraparietalnem sulkusu, je predpogoj za uspešno razumevanje matematike in za razvoj matematičnih kompetenc, ki zahtevajo kompleksno in usklajeno delovanje celotnih možganov.

\section{Literatura}

Ansari, D. (2007). Does the parietal cortex distinguish between »10«, »ten«, and ten dots? Neuron, 53, 165-167.

Arsalidou, M. in Taylor, M. J. (2011). Is $2+2=4$ ? Meta analyses of brain areas needed for numbers and calculations. Neuroimage, 54, 2382-2393.

Blair, K. P., Rosenberg-Lee, M., Tsang, J. M., Schwartz, D. L. in Menon, V. (2012). Beyond natural numbers: Negative number representation in parietal cortex. Frontiers in Human Neuroscience, 6(7). doi: 10.3389/fnhum.2012.00007

Cantlon, J. F. in Brannon, E. M. (2007). How much does number matter to a monkey (Macaca mulatta)? Journal of Experimental Psychology: Animal Behavior Processes, 33(1), 32-41.

Chochon, F., Cohen, L., Moortele, P. F. in Dehaene, S. (1999). Differential contributions of the left and right inferior parietal lobules to number processing. Journal of Cognitive Neuroscience, 11, 617-630.

Cohen Kadosh, R., Bien, N. in Sack, A. T. (2012). Automatic and intentional number processing both rely on intact right parietal cortex: A combined fMRI and neuro-navigated TMS study. Frontiers in Human Neuroscience, 6(2). doi: 10.3389/fnhum.2012.00002

Dehaene, S. (2009). Origins of mathematical intuitions: The case of arithmetic. The Year in Cognitive Neuroscience 2009: Annual NewYork Academy of Science, 1156, 232-259. doi: 10.1111/j.17496632.2009.04469.x

Dehaene, S., Piazza, M., Pinel, P. in Cohen, L. (2003). Three parietal circuits for number processing. Cognitive Neuropsychology, 20(3/4/5/6), 487-506.

Dehaene, S., Molko, N., Cohen, L. in Wilson, A. J. (2004). Arithmetic and the brain. Current Opinion in Neurobiology, 14, 218-224.

De Smedt, B., Holloway, I. D. in Ansari, D. (2011). Effects of problem size and arithmetic operation on brain activation during calculation in children with varying levels of arithmetical fluency. NeuroImage, 57, 771-781. 
Garland, A., Low, J. in Burns, K. C. (2012). Large quantity discrimination by North Island robins (Petroica longipes). Animal cognition, 15, 1129-1140.

Grabner, R. H., Reishofer, G., Koschutnig, K. in Ebner, F. (2011). Brain correlates of mathematical competence in processing mathematical representations. Frontiers in Human Neuroscience, 5(130). doi: 10.3389/fnhum.2011.00130

Houdé, O., Rossi, S., Lubin, A. in Joliot, M. (2010). Mapping numerical processing, reading, and executive functions in the developing brain: An fMRI meta-analysis of 52 studies including 842 children. Developmental Science, 13(6), 876-885.

Jordan, K. E., MacLean, E. L. in Brannon, E. (2008). Monkeys match and tally quantities across senses. Cognition, 108(3), 617-625.

Leighton, T. G., Richards, S. D. in White, P. R. (2004). Marine mammal signals in bubbly water. V Proceedings of the Institute of Acoustics Symposium on Bio-sonar and Bioacoustics Systems. Institute of Acoustics Symposium on Bio-sonar and Bioacoustics Systems, University of Southampton, Institute of Acoustics.

Nieder, A. in Dehaene, S. (2009). Representation of number in the brain. Annual Review of Neuroscience, $32,185-208$.

Pepperberg, I. M. (2002). The Alex Studies: Cognitive and communicative abilities of grey parrots. Cambridge, MA, ZDA: Harvard University Press.

Piazza, M. (2010). Neurocognitive start-up tools for symbolic number representations. Trends in Cognitive Sciences, 14(12), 542-551.

Piazza, M., Pinel, P., Le Bihan, D. in Dehaene, S. (2007). A magnitude code common to numerosities and number symbols in human intraparietal cortex. Neuron, 53, 293-305.

Rugani, R., Fontanari, L., Simoni, E., Regolin L. in Vallortigara G. (2009). Arithmetic in newborn chicks. Proceedings of the Royal Society, 276(1666), 2451-2460.

Stanescu-Cosson, R., Pinel, P., van de Moortele, P. F., Le Bihan, D., Cohen, L. in Dehaene, S. (2000). Understanding dissociation in dyscalculia: A brain imaging study of the impact of number size on the cerebral networks for exact and approximate calculations. Brain, 123, 2240-2255.

Thioux, M., Pesenti, M., De Volder, A. in Seron, X. (2002). Category-specific representation and processing of numbers and animal names across semantic tasks: A PET study. NeuroImage, 13(6 suppl. 2/2), S617. 